\title{
Why people use their cars while the built environment imposes cycling
}

\section{Veronique Van Acker ${ }^{\mathrm{a}}$}

Ghent University

\section{Ben Derudder}

Ghent University
Frank Witlox

Ghent University

\begin{abstract}
:
Residing in a high-density, diverse, and accessible neighborhood tends to be associated with less car use, more public transport, and more cycling and walking. However, this does not hold for all people because of differences in personal perceptions and preferences. This paper, therefore, analyzes spatial (mis)match, or the correspondence between perceptions of someone's residence and the objectively measured spatial characteristics of that residence. Based on a sample for Flanders, Belgium, we found that people tend to overrate the urbanized character of their residence. Among urbanites, (mis)matched spatial perceptions do not influence mode choice. Mode choices remain mainly influenced by urban characteristics and not by personal perceptions as such. However, the influence of spatial (mis)match becomes more important among rural dwellers and, especially, suburbanites. The travel consequences of (mis)matched spatial perceptions thus clearly depend on the residential neighborhood type.
\end{abstract}

Keywords: perceptions, (mis)match, built environment, mode choice, Belgium

\section{Introduction}

Many studies have analyzed the relationship between the built environment and mode choice, but the underlying behavioral mechanisms remain somewhat less well understood. Higher densities, more diversity, and better local accessibility are often believed to result in less car use, more public transport, and more cycling and walking (for a more comprehensive review, see, e.g., Badoe and Miller 2000; Bartholomew and Ewing 2009; Crane 2000; Ewing and Cervero 2001; Handy 2002; Handy 2005; Stead et al. 2000; Stead and Marshall 2001; van Wee 2002; Van Acker and Witlox 2005). However, not all people that reside in high-density, diverse, and accessible neighborhoods travel by definition by public transport or walk and bike instead of using their cars. This is (partly) due to differences in more subjective and behavioral influences such as perceptions (Van Acker et al. 2010). It might be possible that one person perceives the built environment as unsafe, preventing him or her from walking, whereas another person feels it is relatively safe to walk around. Only recently, attempts are being made to incorporate such subjective influences into land-use travel behavior interaction models (e.g., Bagley and Mokhtarian 2002; Kitamura et al. 1997; Scheiner and Holz-Rau 2007; van Wee et al. 2002). However, almost none of these studies question whether these subjective influences correspond to the objective reality. For example, a neighborhood is objectively evaluated as pedestrian friendly (e.g., low motorized-traffic levels, availability of sidewalks), but an individual with a specific lifestyle might still consider this neighborhood unsafe. Therefore, it would be interesting to balance objective variables against more subjective variables. One exception is the series of studies by Schwanen and Moktharian (2005a, 2005b) that focuses on the concept of residential neighborhood-type dissonance, or mismatch between preferred and actual-type residential location. These reports found that travel behavior of the mismatched individuals corresponds to the matched residents of the actual neighborhoods, suggesting that the influence of the built environment remains important despite mismatched spatial preferences. However, it also might be interesting to know how people perceive their current residence and how this corresponds with the objectively measured spatial characteristics of that residential neighborhood. This would offer insights into the accuracy of someone's spatial knowledge about their actual residential neighborhood. For example, the distance between the residence and the nearest bus stop can objectively be measured, but there are no guarantees that a short distance might also be perceived as such. Especially nonpublic transport users might not be aware that a bus stop is within close distance of

\footnotetext{
averonique.vanacker@ugent.be
} 
their residence. In this paper, we will focus on the travel consequences of such (mis)matched spatial perceptions. Therefore, we use data from an Internet survey on lifestyles and leisure mobility in the Flanders region of Belgium, which also questioned the respondents' perceptions of their current residential neighborhood. By adding spatial information from other landuse databases, spatial perceptions can be balanced against the objective spatial characteristics of the respondents' current residential neighborhood. The consequences of the (mis)matched spatial perceptions on mode choice for leisure trips will thus be evaluated.

\section{Data and methodology}

Current travel surveys generally lack information on subjective influences, such as perceptions. Therefore, we conducted an Internet survey between May 2007 and October 2007. In this section, we describe the study background characteristics and the measurement of objective spatial characteristics and subjective spatial perceptions.

\subsection{Description of the sample}

The survey was made known to students and staff members of the University of Antwerp and the Faculty of Sciences at Ghent University, and an announcement was published in the regional information magazines of several villages in the larger urban region of Ghent (Flanders, Belgium). In total, 2,363 people completed the survey, of which 1,878 were retained after data cleaning for further analyses. Figure 1 illustrates the residential locations of these respondents.

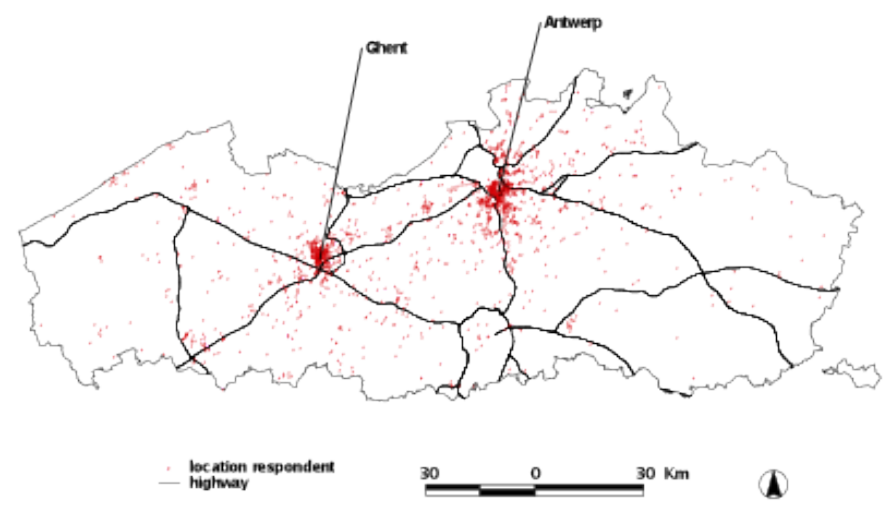

Figure 1. Locations of respondents in Flanders

Despite our efforts, we did not obtain a well-balanced sample as can be seen in Table 1. Women, married couples, people with full-time employment and younger people are overrepresented. But the most remarkable difference is in education. Highly educated respondents are heavily overrepresented in the sample: 66 percent of respondents had a college or university degree, which is considerably higher than the average of 25 percent for Flanders. Although the sample is not representative of the entire population of Flanders, we feel that this does not devalue the sample for our research purposes and results. Our purpose is to model relationships among variables, not to ascertain the univariate distributions of variables in isolation. Our analysis can still properly capture the conditional influence of having a given level of education on travel behavior, even if the proportion of people having that level of education in our sample differs from the population. The sample also permits demonstration of our premise that, conditional on a given level of education, subjective variables, such as personal perceptions, can still explain a significant additional amount of variance in mode choices.

Table 1. Socio-economic and demographic description of the sample

\begin{tabular}{|c|c|c|c|c|}
\hline & \multicolumn{2}{|c|}{ Sample (survey) } & \multicolumn{2}{|c|}{ Reference (Flanders) } \\
\hline $\begin{array}{l}\text { Gender, female } \\
\text { Marital status } \\
\text { single } \\
\text { married/cohabiting } \\
\text { Education } \\
\text { primary school } \\
\text { secondary school, } 3 \text { years } \\
\text { secondary school, } 6 \text { years } \\
\text { college, university } \\
\text { Employment, full-time }\end{array}$ & $\begin{array}{c}0.2 \\
1 . \\
32 . \\
66 . \\
82 .\end{array}$ & & $\begin{array}{l}37.7 \\
62.3 \\
\\
20.7 \\
21.6 \\
33.4 \\
24.7 \\
76.3\end{array}$ & \\
\hline & $\begin{array}{c}0-749 € \\
750-1,499 € \\
1,500-2,249 € \\
2,250-2,999 € \\
3,000-3,749 € \\
3,750-4,499 € \\
4,500-5,249 € \\
5,250-5,999 € \\
+6,000 €\end{array}$ & $\begin{array}{c}9.6 \% \\
6.7 \% \\
14.2 \% \\
18.6 \% \\
24.8 \% \\
13.2 \% \\
6.2 \% \\
3.8 \% \\
2.9 \%\end{array}$ & $\begin{array}{c}0-833 € \\
834-1,666 € \\
1,667-2,500 € \\
2,501-3,333 € \\
3,334-4,166 € \\
+4,167 €\end{array}$ & $\begin{array}{c}19.1 \% \\
32.1 \% \\
21.2 \% \\
10.4 \% \\
6.6 \% \\
10.5 \%\end{array}$ \\
\hline $\begin{array}{l}\text { Possession driving licence } \\
\text { Average age } \\
\text { Average car ownership }\end{array}$ & \multicolumn{2}{|c|}{$\begin{array}{c}81.5 \% \\
30.6 \text { years } \\
1.4 \text { cars/household }\end{array}$} & \multicolumn{2}{|c|}{$\begin{array}{c}81.0 \% \\
40.8 \text { years } \\
1.2 \text { cars/household }\end{array}$} \\
\hline
\end{tabular}

Although the survey was not designed to question perceptions, it contained 16 statements on how respondents perceive their current residential neighborhood. Respondents were first asked to indicate which aspects except price (e.g., quietness, presence of green areas, proximity to work, traffic safety, etc.) would influence a supposed residential location choice. Then, they had to indicate on a five-point Likert scale how satisfied they are with these importantly-rated aspects in their current residential neighborhood. From these 16 statements, we selected only those statements that are relevant and can be related to the physical characteristics of the residential neighborhood (see Figure 2). Statements such as "To what extent are you satisfied with traffic safety in the neighborhood where you currently live?" were thus not selected. Figure 2 illustrates the information that will be used to determine the perceptions of the current residential neighborhood (see section 2.3 Measurement of key variables). 


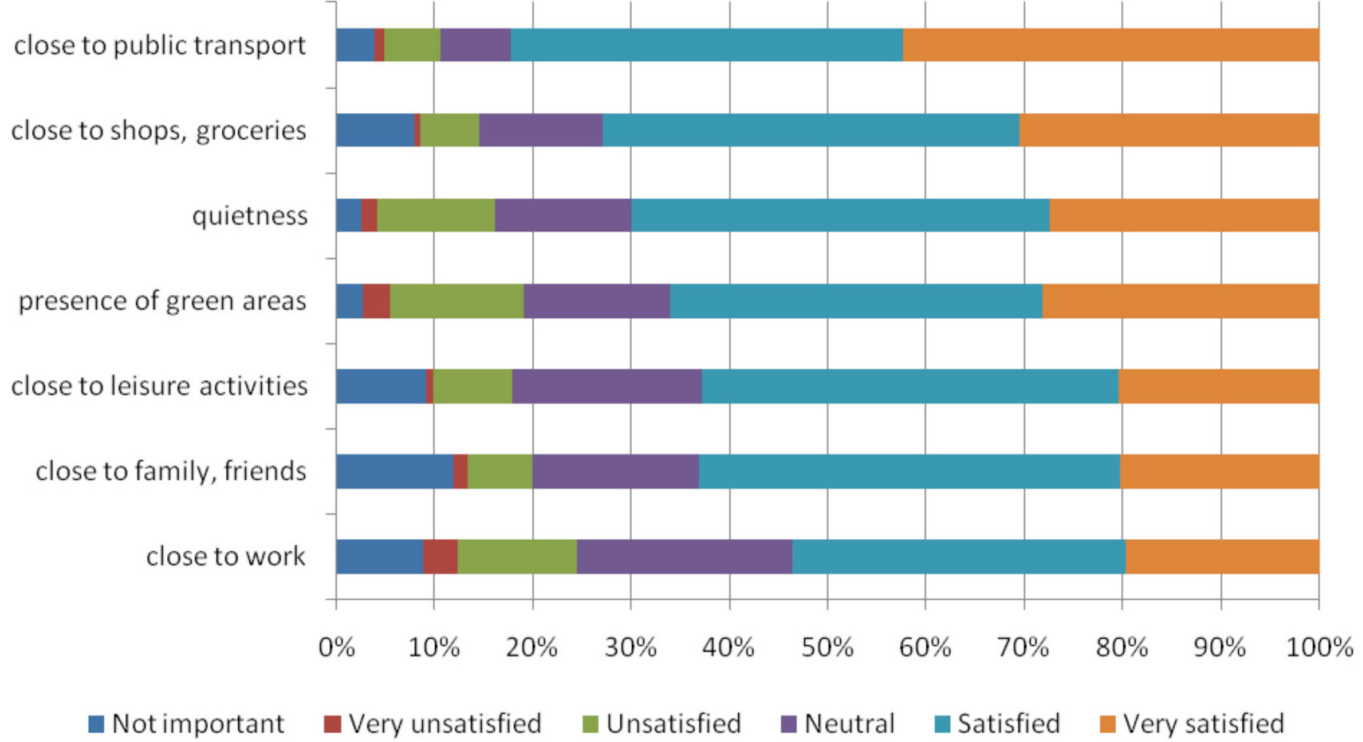

Figure 2. Perception of the current residential neighborhood

\subsection{Factor and cluster analysis}

A correlation analysis revealed significant correlations among the greater part of the statements on perceptions of the residential neighborhood (see Table 2). This indicates that variations in these seven statements on perceptions might reflect the variations in a reduced number of unobserved variables. Factor analysis searches for such joint variations in response to unobserved latent variables (Hair et al., 1998). ${ }^{1}$

Table 2. Spearman rho correlations between the statements on perception of the residential neighborhood

\begin{tabular}{|l|c|l|l|l|l|l|l|}
\hline & $\begin{array}{l}\text { close to } \\
\text { public } \\
\text { transport }\end{array}$ & $\begin{array}{l}\text { close to } \\
\text { shops, } \\
\text { groceries }\end{array}$ & $\begin{array}{l}\text { close to } \\
\text { leisure } \\
\text { activities }\end{array}$ & $\begin{array}{l}\text { close to } \\
\text { family, } \\
\text { friends }\end{array}$ & $\begin{array}{l}\text { close to } \\
\text { work }\end{array}$ & quietness & $\begin{array}{l}\text { presence } \\
\text { of green } \\
\text { areas }\end{array}$ \\
\hline $\begin{array}{l}\text { close to public } \\
\text { transport }\end{array}$ & 1.000 & & & & & & \\
\hline $\begin{array}{l}\text { close to shops, } \\
\text { groceries }\end{array}$ & $0.585^{*}$ & 1.000 & & & & & \\
\hline $\begin{array}{l}\text { close to leisure } \\
\text { activities }\end{array}$ & $0.403^{*}$ & $0.601^{* *}$ & 1.000 & & & & \\
\hline $\begin{array}{l}\text { close to family, } \\
\text { friends }\end{array}$ & $0.233^{*}$ & $0.288^{*}$ & $0.392^{*}$ & 1.000 & & & \\
\hline close to work & $0.289^{*}$ & $0.287^{*}$ & $0.322^{*}$ & $0.249^{*}$ & 1.000 & & \\
\hline quietness & $-0.061^{* *}$ & -0.027 & $0.063^{* *}$ & $0.169^{*}$ & -0.007 & 1.000 & \\
\hline $\begin{array}{l}\text { presence of } \\
\text { green areas }\end{array}$ & $-0.125^{*}$ & $-0.103^{*}$ & -0.015 & $0.122^{*}$ & $-0.097^{*}$ & $0.730^{*}$ & 1.000 \\
\hline
\end{tabular}

Note: ${ }^{\star}$ significant at $\alpha=0.01,{ }^{* *}$ significant at $\alpha=0.05$

In practice, various ways of factoring exist. In our analysis, we used principal axis factoring (PAF), also called common factor analysis or principal factor analysis, since it seeks the least number of factors that account for the common variance of the observed variables. Since the factors are modelled as a linear combination of the observed variables, it is possible to calculate the respondent's score on each factor ("factor scores"). These factor scores are then used to cluster respondents with similar factor scores into reasonably homogenous categories. In other words, this enables us to determine respondents with similar perceptions. After all, cluster analysis is a multivariate technique that classifies objects (in our case, respondents) so that each object is very similar to other objects within the same cluster but different from objects in other clusters (Hair et al., 1998). It minimizes the variance within a cluster but maximizes the variance between clusters.

The combined use of factor and cluster analysis is not new. For example, factorial ecology studies in the 1960s and 1970s first factor analyzed various spatial characteristics to reduce the dimensionality in the dataset and then cluster analyzed the new factors to identify urban subareas (e.g., Dakin, 1971; Johnston, 1978). Our methodology for determining spatial perceptions is clearly inspired by such work.

\subsection{Measurement of key variables}

\subsubsection{Subjective spatial perceptions}

The seven statements on perceptions of the residential neighborhood are significantly correlated with each other, indicating that factor analysis might be useful to reduce this dimensionality and retrieve the underlying factors. The scores on these statements were therefore factor analyzed (principal axis fac-

\footnotetext{
${ }^{1}$ Factor analysis is related to principal component analysis (PCA), but the two are not identical. One important conceptual difference is that PCA simply considers the latent unobserved variables as a combination of the observed variables, whereas factor analysis considers the observed variables as expression of the underlying latent factors. This also implies that PCA analyzes the total variance of the observed variables, whereas factor analysis only uses the common variance (= "communality").
} 
toring, promax rotation, 39.4 percent variance explained) into two underlying dimensions that influence how respondents perceive their residence (see Table 3): (i) having access to various facilities (probably reflecting urban perceptions), and (ii) the presence of open space and quietness (probably reflecting suburban or rural perceptions). The number of factors in our analysis is chosen based on interpretation of the scree plot, eigenvalues larger than one, and especially, interpretability of the factors.

Table 3. Pattern matrix for perception factors

\begin{tabular}{|c|c|c|}
\hline $\begin{array}{l}\text { Perception factor } \\
\text { To what extent are you } \\
\text { satisfied with these aspects } \\
\text { of the neighborhood were } \\
\text { you currently live? }\end{array}$ & 绨 & 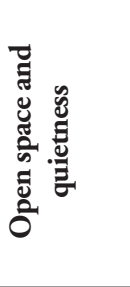 \\
\hline $\begin{array}{l}\text { close to leisure activities } \\
\text { close to shops, groceries } \\
\text { close to public transport } \\
\text { close to work } \\
\text { close to family, friends }\end{array}$ & $\begin{array}{l}0.701 \\
0.681 \\
0.461 \\
0.367 \\
0.365\end{array}$ & \\
\hline $\begin{array}{l}\text { quietness } \\
\text { presence of green areas }\end{array}$ & & $\begin{array}{l}0.811 \\
0.801\end{array}$ \\
\hline
\end{tabular}

Note: Only factor loadings higher than 0.300 (in magnitude are reported since these loadings characterize the factors to a large extent.

In a subsequent step, respondents with similar scores on these two perception factors were grouped together by means of a cluster analysis (Ward's method, squared Euclidean distance). The number of clusters is based on the interpretation of a graph in which the within-cluster sum of squares is plotted against the number of clusters (a sharp change may be indicative of the best solution) and, especially, interpretability of the clusters. Doing so, we found three clusters reflecting whether respondents perceive their residential neighborhoods as urban, suburban, or rural (see Table 4). This three clusters solution suggests a clear contrast between urban and rural perceptions. Urban perceptions are characterized by high ratings of accessibility and low ratings of open space and quietness, whereas the opposite holds for rural perceptions. A third cluster combines high ratings of accessibility with high ratings of open space and quietness. This refers to a combination of urban as well as rural perceptions, which we labeled "suburban." This suburban perception obtains higher ratings of accessibility and open space and quietness compared to urban and rural perceptions, respectively, which might seem awkward. However, we should keep in mind that the scores in Table 4 refer to perceptions, which does not mean that overall accessibility is better in suburban areas compared to urban neighborhoods or that suburban areas have more open spaces than rural neighborhoods. Furthermore, the survey questioned how satisfied respondents are with their current residential neighborhood. It might be possible that suburban residents are more satisfied and enjoy the mix of positive urban and rural aspects (i.e., accessibility and open space and quietness, respectively) to a greater extent than their urban and rural counterparts.

The reliability of the internal consistency of these three clusters has been tested by a split-run procedure (Punj and Stewart, 1983). We randomly divided the original sample in two smaller subsamples and repeated the cluster analysis for each subsample. The results of the cluster analyses based on the smaller subsamples confirmed our previous results. Moreover, ANOVA results suggest that at least two of the three clusters have significantly different scores on the accessibility factor (F $=979.704, \mathrm{p}<0.001)$, and the same conclusion holds for the open space and quietness factor $(\mathrm{F}=862.947, \mathrm{p}<0.001) .2$

We also considered a four clusters solution. It suggested a continuum ranging from urban to rural perceptions but with more diversity in the previous "suburban" cluster. The results indicated that some respondents perceive their neighborhood as suburban but with some urban characteristics as well, whereas others perceive it as suburban with some rural characteristics. However, this solution was not retained because the results were not confirmed by the split-run procedure.

Table 4. Description of the perception clusters

\begin{tabular}{|l|c|c|c|}
\hline Perception cluster & & & \\
& & & \\
& & 5 & \\
Perception factor $\vee$ & & & \\
\hline accessibility & & 0.434 & -1.316 \\
open space and quietness & -1.112 & 0.608 & 0.175 \\
\hline $\mathbf{N}$ & $\mathbf{5 2 9}$ & $\mathbf{8 7 8}$ & $\mathbf{3 1 4}$ \\
\hline
\end{tabular}

\subsubsection{Objective spatial characteristics}

By geocoding the respondent's address, we could add spatial information from various land-use and transportation databases to calculate several spatial characteristics of the respondent's residence. For this study, we calculated two additional spatial characteristics that can be related to the seven statements on spatial perception of the residential neighborhood (see also Van

${ }^{2}$ The F-test should be used only for descriptive purposes because the clusters have been chosen to maximize the differences among respondents in different clusters. the reported significance levels are not corrected for this. 
Acker and Witlox 2010, 2011): (i) local potential accessibility and (ii) built-up index. Accessibility can be measured in various ways, but always refers to the ability "to reach activities or locations by means of a (combination of) travel mode(s) (Geurs and van Wee, 2004). We used a "potential accessibility" measure that is a simple but commonly used accessibility measure. It calculates the number of activities that can be reached in a certain amount of time, weighted for travel time. We used the number of people that can be reached by car within five minutes as a proxy for local potential accessibility. For each residence, accessibility is calculated using the regional travel demand forecasting model Multimodal Model Flanders. It is basically the sum of the number of people in every census tract in the region, weighted by the travel time from the residence to these census tracts. Travel time is calculated in ArcGIS 9.2 as the fastest path by car along the road network. We restricted this travel time to five minutes to detect differences in local accessibility. After all, our study area has a limited geographical scale so that differences in accessibility are more important on a local level (e.g., within five minutes) than a regional level (e.g., within 60 minutes). We are aware that accessibility is more than just having access to people. However, we lacked detailed and geocoded information on, for example, the location of leisure activities (which would be more relevant for our analysis of mode choices for leisure trips). Consequently, we limit our potential accessibility measure to having access to people. The built-up index equals the percentage of built-up surface at the census tract level. It can be considered a proxy for built-up density. It is derived from the land-use database of the Agency of Spatial Information Flanders, which offers a categorization between built-up surfaces and open surfaces. Table 5 presents some descriptive statistics of these two spatial characteristics.

Table 5. Description of the spatial characteristics

\begin{tabular}{|l|c|c|c|c|}
\hline & Min. & Max. & Average & Std. Dev. \\
\hline local accessibility (\# people) & 1,140 & 287,950 & 35,720 & $32,820.3$ \\
\hline built-up index (\%) & 0.00 & 1.00 & 0.54 & 0.307 \\
\hline
\end{tabular}

By performing a cluster analysis (Ward's method, squared Euclidean distance), neighborhoods with similar scores on these two spatial characteristics are grouped together so that the clusters describe various residential neighborhood types. The number of clusters is based on the interpretation of a graph in which the within-cluster sum of squares is plotted against the number of clusters (a sharp change may be indicative of the best solution) and, especially, interpretability of the clusters. Doing so, we found three clusters that also reflected a continuum ranging from urban to suburban to rural neighborhoods (see Table 6). Urban neighborhoods are characterized by high levels of accessibility (i.e., many people can be reached by car within five minutes) and high percentages of built-up area, whereas the opposite holds for rural neighborhoods. A third cluster falls in between with moderate levels of accessibility and moderate percentages of built-up area. In other words, local accessibility and built-up density increases with increasing urbanization as could be expected.

Reliability of the internal consistency of these three spatial clusters has been confirmed by a split-run procedure as has the cluster analysis of the spatial perceptions. Moreover, ANOVA results suggest that at least two of the three clusters have significantly different scores on the local accessibility factor $(\mathrm{F}=241.445, \mathrm{p}<0.001)$, and the same conclusion holds for the built-up index $(\mathrm{F}=1890.002, \mathrm{p}<0.001) .3$

We also considered a four clusters solution. It suggested a continuum ranging from urban to rural neighborhoods, but with more diversity in the previous "urban" cluster, which was divided between a highly and more moderate urbanized cluster. This solution was also confirmed by the split-run procedure. Nevertheless, we decided to reject this solution because the highly urbanized cluster consisted of only eight neighborhoods (mainly city centers with extremely high percentages of built-up area).

Table 6. Description of neighborhood clusters

\begin{tabular}{|c|c|c|c|}
\hline $\begin{array}{l}\text { Spatial cluster } \\
\text { Spatial characteristic } \vee\end{array}$ & 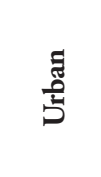 & 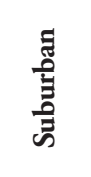 & 牙 \\
\hline $\begin{array}{l}\text { local accessibility } \\
\text { built-up index }\end{array}$ & $\begin{array}{c}114,026 \\
0.88\end{array}$ & $\begin{array}{c}54,396 \\
0.73\end{array}$ & $\begin{array}{c}17,400 \\
0.41\end{array}$ \\
\hline $\mathbf{N}$ & 90 & 274 & 664 \\
\hline
\end{tabular}

\section{3 (Mis)matched spatial perceptions and their travel consequences}

After having specified the respondents' spatial perceptions and the diverse neighborhood types, we can balance these against each other and determine whether respondents perceive their residence in a correct way.

\subsection{Size of (mis)matched spatial perceptions}

Table 7 illustrates that almost 40 percent of all respondents correctly perceive their residential neighborhood (see figures in gray, on the diagonal) and have, what we call, matched spatial perceptions. The large amount of spatial mismatch is thus

\footnotetext{
${ }^{3}$ The F-test should be used only for descriptive purposes because the clusters have been chosen to maximize the differences among neighborhoods in different clusters. The reported significance levels are not corrected for this.
} 
striking. Moreover, respondents tend to overrate the urbanized character of their residence (see larger figures in red compared to figures in green). For example, more than half of all respondents who reside in a rural neighborhood perceive their residence as suburban, whereas this figure is only 10 percent in the reverse situation (residing in a suburban neighborhood but perceiving it as rural). This urbanized perception can be explained by the long-lasting tradition of suburbanization that exists in Belgium and goes back to the nineteenth century. After all, influenced by its housing policy and transport policy, a commuting culture has always existed in Belgium. Due to inexpensive public transport season tickets and a wellestablished network of railways and tramways, people were no longer compelled to reside near their jobs located within the city, and they moved toward green, safe, and quiet residential neighborhoods outside the city center. This was even more encouraged by housing policy that promoted inexpensive social house construction in garden cities and provided subsidies and fiscal compensations for individual homeownership. As a consequence, some form of suburbanization already existed in Belgium from the second half of the nineteenth century (Boussauw et al. 2009; Kesteloot 2003; Lauwers 1991; Verhetsel et al. 2007). This process of extensive suburbanization led to a highly fragmented urbanized space, evoking the impression that every square meter is densely built up.

Table 7. Size of (mis)matched spatial perceptions

\begin{tabular}{|c|c|c|c|c|c|}
\hline \multicolumn{2}{|c|}{$\begin{array}{l}\text { Perception cluster } \\
\text { Spatial cluster }\end{array}$} & Urban & Suburban & Rural & Total \\
\hline Urban & $\begin{array}{l}\mathrm{N} \\
\% \text { within spatial cluster } \\
\% \text { within perception cluster } \\
\% \text { of Total }\end{array}$ & \begin{tabular}{|c|}
170 \\
$53.5 \%$ \\
$33.3 \%$ \\
$10.5 \%$
\end{tabular} & $\begin{array}{c}121 \\
38.1 \% \\
14.6 \% \\
7.4 \%\end{array}$ & $\begin{array}{l}27 \\
8.5 \% \\
9.4 \% \\
1.7 \%\end{array}$ & $\begin{array}{c}318 \\
100.0 \% \\
19.6 \% \\
19.6 \%\end{array}$ \\
\hline Suburban & $\begin{array}{l}\mathrm{N} \\
\% \text { within spatial cluster } \\
\% \text { within perception cluster } \\
\% \text { of Total }\end{array}$ & \begin{tabular}{c|}
202 \\
$40.9 \%$ \\
$39.6 \%$ \\
$12.4 \%$ \\
\end{tabular} & \begin{tabular}{|c|c|}
239 & \\
$48.4 \%$ \\
$28.8 \%$ \\
$14.7 \%$
\end{tabular} & $\begin{array}{c}53 \\
10.7 \% \\
18.5 \% \\
3.3 \%\end{array}$ & $\begin{array}{c}494 \\
100.0 \% \\
30.4 \% \\
30.4 \%\end{array}$ \\
\hline Rural & $\begin{array}{l}\mathrm{N} \\
\% \text { within spatial cluster } \\
\% \text { within perception cluster } \\
\% \text { of Total }\end{array}$ & $\begin{array}{c}138 \\
17.0 \% \\
27.1 \% \\
8.5 \%\end{array}$ & $\begin{array}{c}469 \\
57.6 \% \\
56.6 \% \\
28.8 \%\end{array}$ & \begin{tabular}{r|}
207 \\
$25.4 \%$ \\
$72.1 \%$ \\
$12.7 \%$
\end{tabular} & $\begin{array}{c}814 \\
100.0 \% \\
50.1 \% \\
50.1 \%\end{array}$ \\
\hline Total & $\begin{array}{l}\mathrm{N} \\
\% \text { within spatial cluster } \\
\% \text { within perception cluster } \\
\% \text { of Total }\end{array}$ & $\begin{array}{c}510 \\
31.4 \% \\
100.0 \% \\
31.4 \%\end{array}$ & $\begin{array}{c}829 \\
51.0 \% \\
100.0 \% \\
51.0 \%\end{array}$ & $\begin{array}{c}287 \\
17.7 \% \\
100.0 \% \\
17.7 \%\end{array}$ & $\begin{array}{c}1,626 \\
100.0 \% \\
100.0 \% \\
100.0 \%\end{array}$ \\
\hline
\end{tabular}

In section 3.2, "(Mis)matched spatial perceptions and mode choice," we describe how mode choices might differ among respondents with matched and mismatched spatial perceptions. However, any association between spatial perception mismatch and mode choice might also be the result of various sample biases (e.g., the overrepresentation of highly educated people). Table 8 , however, illustrates that no significant socio-economic and demographic differences exist between matched and mismatched respondents.
Table 8. Differences between matched and mismatched respondents

\begin{tabular}{|c|c|c|c|c|}
\hline & $\begin{array}{l}\text { Matched } \\
\text { respondents }\end{array}$ & $\begin{array}{l}\text { Mismatched } \\
\text { respondents }\end{array}$ & $\chi^{2}$ (sig.) & Cramer's V \\
\hline $\begin{array}{l}\text { Gender, } \\
\text { female } \\
\text { Marital status, } \\
\text { married/cohabiting } \\
\text { Education, } \\
\text { college, university } \\
\text { Employment, } \\
\text { full-time } \\
\text { Monthly household income } \\
0-749 € \\
750-1,499 € \\
1,500-2,249 € \\
2,250-2,999 € \\
3,000-3,749 € \\
3,750-4,499 € \\
4,500-5,249 € \\
5,250-5,999 € \\
+6,000 € \\
\text { Possession driving license }\end{array}$ & $\begin{array}{c}11.2 \% \\
6.9 \% \\
12.8 \% \\
=16.9 \% \\
26.5 \% \\
13.6 \% \\
5.9 \% \\
3.3 \% \\
2.9 \% \\
82.6 \%\end{array}$ & $\begin{array}{c}8.7 \% \\
6.5 \% \\
15.7 \% \\
20.0 \% \\
24.0 \% \\
12.5 \% \\
5.9 \% \\
3.7 \% \\
2.9 \% \\
80.2 \%\end{array}$ & $\begin{array}{l}2.274(0.132) \\
0.071(0.789) \\
2.172(0.141) \\
1.986(0.159) \\
1.051(0.305) \\
0.291(0.589) \\
0.000(0.982) \\
0.132(0.717) \\
0.002(0.963) \\
1.464(0.226)\end{array}$ & $\begin{array}{l}0.041 \\
0.007 \\
0.040 \\
0.038 \\
0.028 \\
0.015 \\
0.001 \\
0.010 \\
0.001 \\
0.030\end{array}$ \\
\hline & $\begin{array}{l}\text { Matched } \\
\text { respondents }\end{array}$ & $\begin{array}{l}\text { Mismatched } \\
\text { respondents }\end{array}$ & F (sig.) & \\
\hline $\begin{array}{l}\text { Average age } \\
\text { Average car ownership }\end{array}$ & $\begin{array}{c}30.4 \text { years } \\
1.4 \\
\text { cars/household }\end{array}$ & $\begin{array}{c}29.7 \text { years } \\
1.4 \\
\text { cars/household }\end{array}$ & $\begin{array}{l}1.669(0.197) \\
2.567(0.109)\end{array}$ & \\
\hline
\end{tabular}

\section{2 (Mis)matched spatial perceptions and mode choices}

We start our analysis of mode choices with the formulation of two possible hypotheses. Several studies point out that subjective influences, such as perceptions, are important determinants of mode choices (e.g., Gärling et al. 1998; Golob et al. 1979; Parkany et al. 2004; Tardiff 1977; Thogersen 2006). Consequently, it seems plausible that respondents with mismatched perceptions will choose those travel modes that correspond with their spatial perceptions. For example, someone residing in a suburban neighborhood but perceiving it as urban might be more likely to use public transport or walk and bike than his matched neighbor. In other words, mode choices of this mismatched suburbanite correspond more to the mode choices of a matched urbanite (see Hypothesis 1). However, if perceptions are not crucial to mode choices, the influence of the residential neighborhood itself might become more important. If this is the case, then all inhabitants within a particular neighborhood type should make similar mode choices, despite any (mis)matched spatial perceptions (see Hypothesis 2).

- Hypothesis 1: Spatial perceptions are crucial

- Hypothesis 2: Residential neighborhood is crucial

Our data suggests that both hypotheses are true, depending on the neighborhood type and spatial perception considered (see Figure 4). But when discussing the results, we should keep in mind that our sample is skewed toward highly educated young adults, women, and full-time employees. Repeat- 

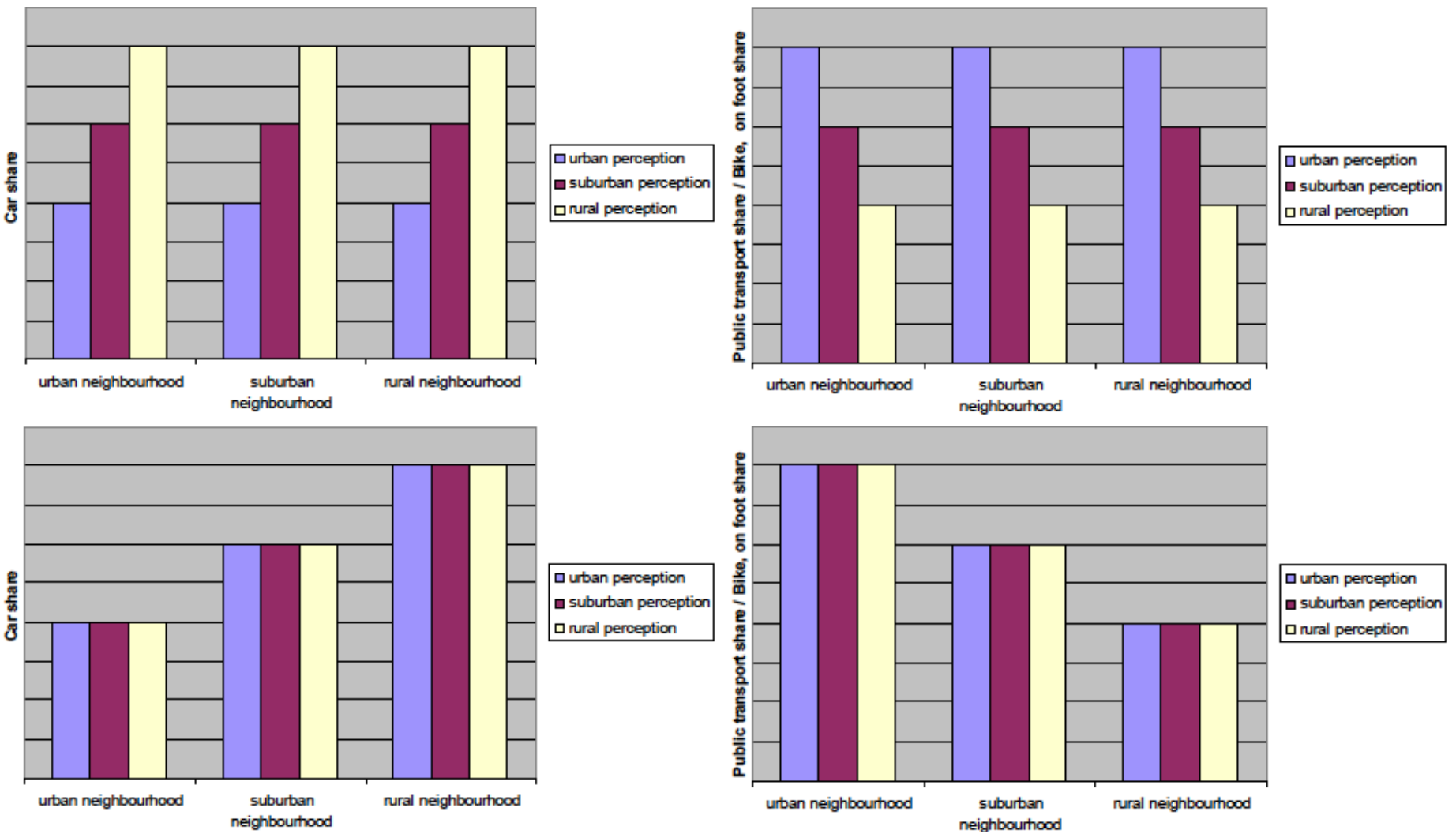

Figure 3. Hypothesized relationships between (mis)matched spatial perceptions and mode choices

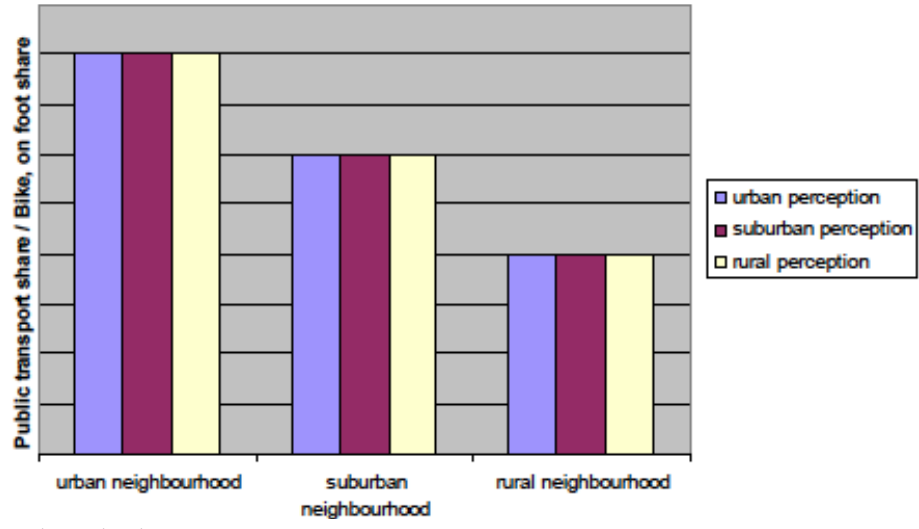

ing the analysis based on a sample that is representative for the whole of Flanders could lead to somewhat different results.

For example, residing in an urban neighborhood clearly discourages car use (4a). Car use is almost equally high for all respondents residing in an urban neighborhood. Whether someone perceives this neighborhood as urban or not, it seems not to influence the decision to use the car. An urban residential neighborhood is clearly an important determinant of car use. However, this does not hold for a suburban or rural neighborhood. Perceptions become more important. A suburban resident who perceives his or her residence as urban (rural), tends to act as a matched urbanite (matched rural dweller) and uses less often (more often) the car.

The influence of (mis)matched spatial perceptions on the share of public transport (4b) and walking/cycling (4c) is less obvious. At first glance, it seems that an urban neighborhood encourages the use of public transport and walking/cycling. Even though some mismatched urbanites perceive their urban residence as suburban, they rather behave as matched urbanites and are more likely to use public transport and walk/cycle more often than they actually would do so by virtue of their spatial perception. This association is less clear for mismatched urbanites who perceive their neighborhood as rural (instead of urban). Their share of public transport and walking/cycling is lower than that of a matched urbanite (suggesting that it is not only about the spatial environment), yet still considerably higher than a matched rural dweller (suggesting that perceptions also are not the only influences). More or less similar patterns are found for rural dwellers, but mode choices of suburban dwellers are clearly more influenced by spatial perceptions than by the suburban neighborhood itself. Mismatched suburbanites have similar mode choices to their matched counterparts. For example, someone who perceives his or her suburban residence as urban (rural) also behaves as a matched urbanite (rural dweller) and chooses more often (less often) to use public transport and to walk/cycle. 

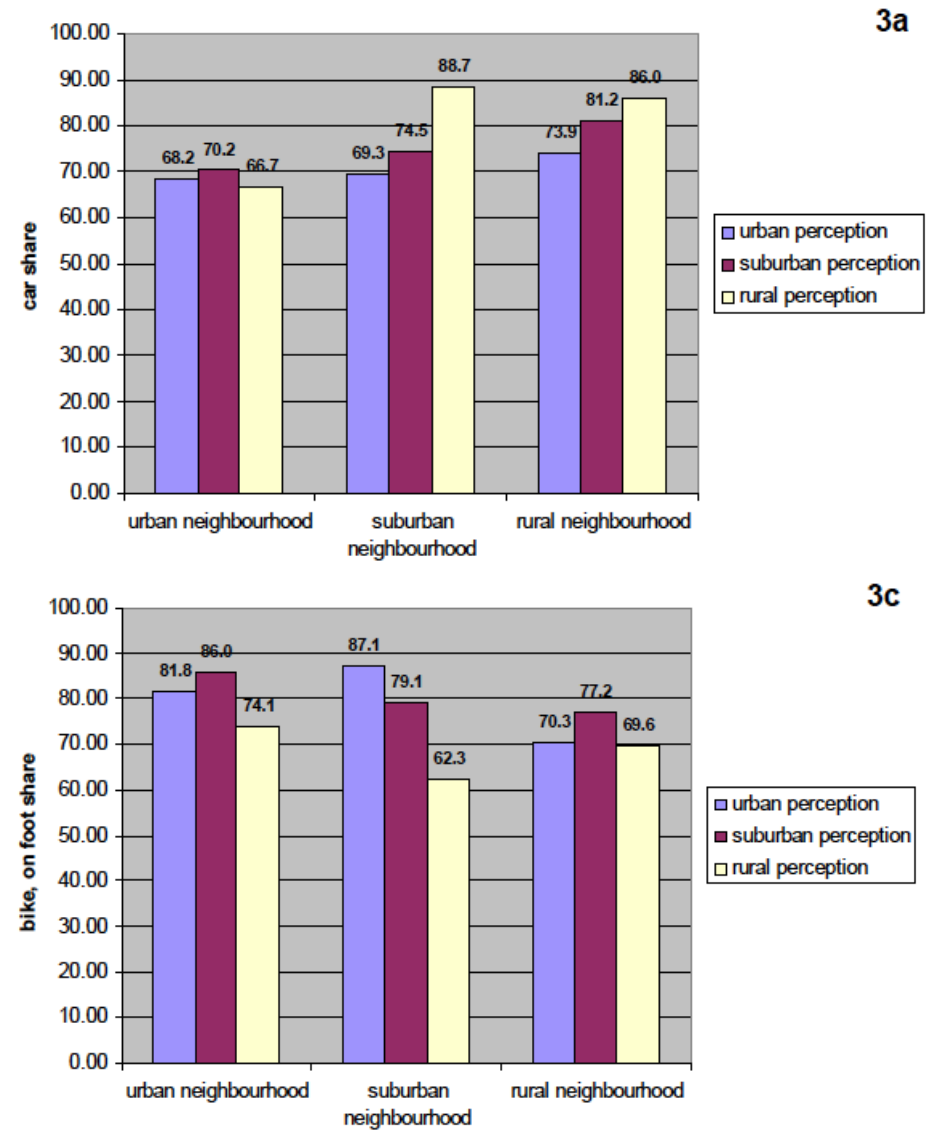

Figure 4. Influence of (mis)matched spatial perceptions on mode choices

\section{Conclusions}

This paper aims to contribute to the research on the interaction between the built environment and travel behavior by evaluating the objective and subjective spatial influences of mode choices. Whereas most studies only use objectively measured variables such as population density, land-use mix, and accessibility to characterize the built environment, some researchers recently argued in favor of including more subjective variables as well. After all, due to differences in more subjective and behavioral influences, such as individual perceptions, it remains possible that not all urban dwellers travel by definition by public transport or walk and bike more often compared to their suburban and rural counterparts. Whereas one person might perceive his or her residence as unsuitable to walk or cycle around, another person might perceive this in a totally different way. Recent land-use travel behavior interaction studies have been aware of such subjective influences but tend to neglect the question whether these subjective influences correspond to the objective reality. Therefore, this paper aimed at describing the size of spatial (mis)match between perceptions and reality in the first place.

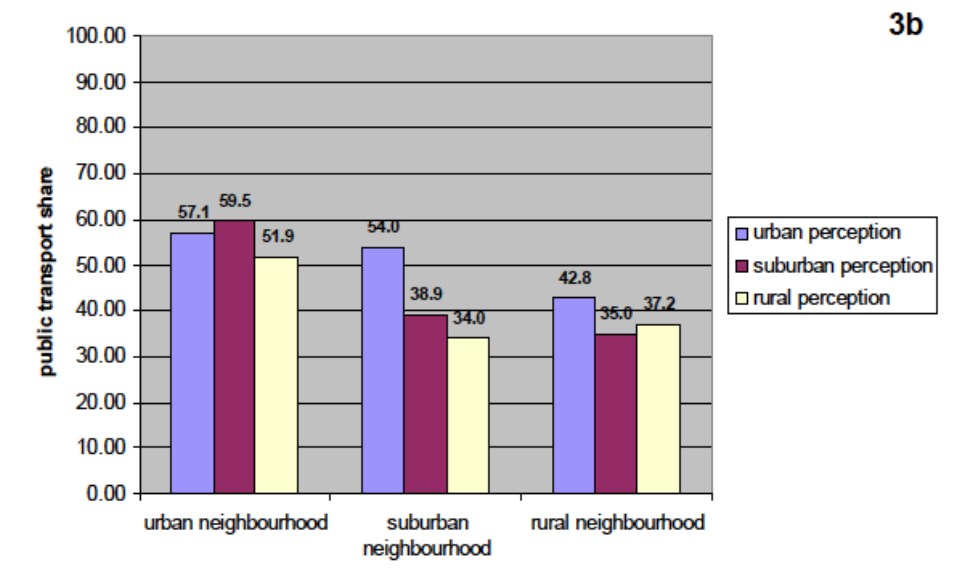

$3 b$

\section{.

\section{.

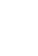


residents are thus able to choose for those travel modes that fit within their perception of the residence. However, spatial perceptions are not always the only determinants of mode choices. In other cases, the residential neighborhood itself becomes more important. Especially in urban neighborhoods, it seems that high densities and high local accessibility almost automatically result in a lower car share, a higher public transport share, and more walking and cycling. Differences in how respondents perceive their urban residence seemed less important: matched and mismatched urbanites tend to make similar mode choices. The influence of (mis)matched spatial perceptions thus clearly depends on the residential neighborhood type and the travel mode considered.

This paper presents a preliminary analysis of spatial (mis) match and provides some insights into a new interesting topic that deserves more attention. However, our analysis suffers from some limitations of which the lack of statistical representativeness seems the most important. Our sample is skewed toward highly educated young adults, women, and full-time employees. The conclusions can therefore only be understood correctly in reference to this specific sample. Furthermore, the original data were not collected for the specific research questions raised in this paper. This might influence the results of the factor and cluster analysis that determined the spatial perceptions. Furthermore, the typology of residential neighborhoods was based on only two spatial characteristics (accessibility and percentage of built-up area because these two characteristics were in line with the previously found spatial perceptions). However, such spatial typology can be based on many more spatial characteristics, which can be measured in different ways (e.g., accessibility for which many indicators exists). Extending our preliminary analysis with other spatial characteristics and indicators might provide us with a better understanding of the consequences of spatial (mis)match.

Based on our findings, one important recommendation can be made for spatial planning policies. Spatial planning policies aimed at achieving high density and providing facilities at the neighborhood level can contribute to a more sustainable mobility (less car use, more public transport, more walking and cycling), especially if these policies are developed in an urban neighborhood. After all, our findings suggest that within such an urban neighborhood, mode choices are mainly influenced by the urban characteristics and not by personal perceptions as such. However, our results also point out similar planning policies developed outside an urban neighborhood will not automatically have the same result and will only be successful for a specific group of residents that perceive their residence as urban.

\section{REFERENCES}

Badoe, D. A. and E. J. Miller. 2000. Transportation-land use interaction: Empirical findings in North America, and their implications for modelling. Transportation Research D, 5(4): 235-263. doi:10.1016/S1361-9209(99)00036-X.

Bagley, M. N. and P. L. Mokhtarian. 2002. The impact of residential neighborhood type on travel behavior: A structural equations modeling approach. Annals of Regional Science, 36(2): 279-297. doi:10.1007/s001680200083.

Bartholomew, K. and R. Ewing. 2009. Land use-transportation scenarios and future vehicle travel and land consumption. Journal of the American Planning Association, 75(1): 13-27. doi:10.1080/01944360802508726.

Boussauw, K., E. Zwerts, and F. Witlox. 2009. "Mobiel Vlaanderen." In: L. Vanderleyden, M. Callens and J. Noppe (eds.), De sociale staat van Vlaanderen, 279-312. Brussels: Studiedienst van de Vlaamse Regering. [in Dutch]

Crane, R. 2000. The influence of urban form on travel: An interpretive review. Journal of Planning Literature, 15(1): 3-23. doi:10.1177/08854120022092890.

Dakin, A. J. 1971. Murdie, Robert A. "Factoral ecology of metropolitan Toronto 1951-1961" (Book review). Town Planning Review, 42(1): 100-101. http://liverpool.metapress. com/content/y92jv1067u17v111/fulltext.pdf.

Ewing, R. and R. Cervero. 2001. Travel and the built environment: A synthesis. Transportation Research Record, 1780: 87-114. doi:10.3141/1780-10.

Gärling T., R. Gillhom, and A. Gärling. 1998. Reintroducing attitude theory in travel behaviour research: The validity of an interactive interview procedure to predict car use. Transportation, 25(2): 129-146. doi:10.1023/A:1005004311776.

Geurs, K., and B. van Wee. 2004. Accessibility evaluation of land-use and transport strategies: review and research directions. Journal of Transport Geography, 12(2): 127-140. doi:10.1016/j.jtrangeo.2003.10.005.

Golob, T. F., A. D. Horowitz, and M. Wachs. 1979. Attitudebehavior relationships in travel demand modeling. In: D. A. Hensher and P. R. Stopher (eds.), Behavioural Travel Demand Modeling, 739-757. London: Croom Helm.

Hair, J. F. Jr., R. E. Anderson, R. L. Tatham, and W. C. Black. 1998. Multivariate data analysis. Upper Saddle River, NJ: Prentice Hall.

Handy, S. 2002. Travel behaviour-land use interactions: An overview and assessment of the research. In: H. S. Mahmassani (ed.), In perpetual motion: Travel behavior research opportunities and application challenges, 223-236. Amsterdam: Pergamon. 
Handy, S. 2005. Critical assessment of the literature on the relationships among transportation, land use and physical activity. Washington D.C.: Transportation Research Board.

Johnston, R. J. 1978. Residential area characteristics: Research methods for identifying urban sub-areas analysis and factorial ecology. In: D.T. Herbert, and R.J. Johnston (eds.), Social areas in cities: Processes, patterns and problems, 175-217. Chichester, England: John Wiley and Sons.

Kesteloot C. 2003. Verstedelijking in Vlaanderen: Problemen, kansen en uitdagingen voor het beleid in de 21ste eeuw. In: L. Boudry, P. Cabus, E. Corijn, E. De Rynck, C. Kesteloot, and A. Loeckx (eds.), De eeuw van de stad, 15-39. Brussels: Ministerie van de Vlaamse Gemeenschap. [in Dutch]

Kitamura, R., P. L. Mokhtarian, and L. Laidet. 1997. A microanalysis of land use and travel in five neighborhoods in the San Francisco Bay Area. Transportation, 24(2): 125-158. doi:10.1023/A:1017959825565.

Lauwers D. 1991. Ruimtelijke aspecten van de fileproblematiek. In: R. Poté (ed.), Files in Vlaanderen, 48-60. Leuven, Belgium: Garant. [in Dutch]

Parkany E., R. Gallagher, and P. Viveiros. 2004. Are attitudes important in travel choice? Transportation Research Record, 1984: 127-139. doi:10.3141/1894-14.

Punj, G. N. and D. W. Stewart. 1983. Cluster analysis in marketing research: Review and suggestions for application. Journal of Marketing Research, 20: 134-148. doi:10.2307/3151680.

Scheiner J. and C. Holz-Rau. 2007. Travel mode choice: Affected by objective or subjective determinants? Transportation, 34(4): 487-511. doi:10.1007/s11116-007-9112-1.

Schwanen, T. and P.L. Mokhtarian. 2005a. What if you live in the wrong neighborhood? The impact of residential neighborhood type dissonance on distance traveled. Transportation Research D, 10(2): 127-151. doi:10.1016/j. trd.2004.11.002

Schwanen, T., and P. L. Mokhtarian. 2005b. What affects commute mode choice: Neighborhood physical structure or preferences toward neighborhoods? Journal of Transport Geography, 13(1): 83-99. doi:10.1016/j.jtrangeo.2004.11.001.

Stead, D. and S. Marshall. 2001. The relationships between urban form and travel patterns: An international review and evaluation. European Journal on Transport Infrastructure and Research, 1(2): 113-141. http://www.ejtir.tbm.tudelft.nl/ issues/2001_02/pdf/2001_02_01.pdf

Stead, D., J. Williams, and H. Titheridge. 2000. Land use, transport and people: Identifying the connections. In: K. Williams, E. Burton, and M. Jenks (eds.), Achieving Sustainable Urban Form, 174-186. London: E. and F.N. Spon.
Tardiff, T. J. 1977. Causal inferences involving transportation attitudes and behavior. Transportation Research, 11(6): 397404. doi:10.1016/0041-1647(77)90004-1.

Thogersen, J. 2006. Understanding repetitive travel mode choices in a stable context: A panel study approach. Transportation Research A, 40(8): 621-638. doi:10.1016/j. tra.2005.11.004.

Van Acker, V., B. van Wee, and F. Witlox. 2010. When transport geography meets social psychology: Toward a conceptual model of travel behaviour. Transport Reviews, 30(2): 219-240. doi:10.1080/01441640902943453.

Van Acker, V. and F. Witlox. 2005. Exploring the relationships between land-use system and travel behaviour concepts: some first findings. Solstice, 16(1): 1-18. http://hdl.handle. net $/ 2027.42 / 60310$

Van Acker, V. and F. Witlox. 2010. Car ownership as a mediating variable in car travel behaviour research using a structural equation modelling approach to identify its dual relationship. Journal of Transport Geography, 18(1): 65-74. doi:10.1016/j.jtrangeo.2009.05.006.

Van Acker, V. and F. Witlox. 2011. Commuting trips within tours: How is commuting related to land use? Transportation, 38(3): 465-486. doi:10.1007/s11116-010-9309-6.

van Wee, B. 2002. Land use and transport: Research and policy challenges. Journal of Transport Geography, 10(4): 259-271. doi:10.1016/S0966-6923(02)00041-8.

van Wee, B., H. Holwerda, and R. van Baren. 2002. Preferences for modes, residential location and travel behaviour: The relevance for land-use impacts on mobility. European Journal on Transport and Infrastructure Research, 2(3/4): 305-316. http://www.ejtir.tbm.tudelft.nl/issues/2002_03-04/ pdf/2002_03-04_08.pdf.

Verhetsel, A., I. Thomas, and M. Beelen. 2007. De kracht van het Alonso-Muth model. Het woon-werkverkeer in en rond de Belgische grootsteden. Ruimte en Planning, 27(3): 9-28. 